\title{
Immunotherapeutic approaches for treatment of brain tumors
}

\author{
Terry Lichtor \\ Neurological Surgery, Rush University, Rush Medical College, Rush University Medical Center in Chicago, Illinois 60612, USA. \\ Correspondence to: Dr. Terry Lichtor, Neurological Surgery, Rush University, Rush Medical College, Rush University Medical Center in \\ Chicago, Illinois 60612, USA. E-mail: Terry_Lichtor@rush.edu
}

How to cite this article: Lichtor T. Immunotherapeutic approaches for treatment of brain tumors. Neuroimmuno/ Neuroinflammation 2019;6:2. http://dx.doi.org/10.20517/2347-8659.2018.67

Received: 21 Nov 2018 Accepted: 22 Nov 2018 Published: 16 Jan 2019

Science Editor: Athanassios P. Kyritsis Copy Editor: Huan-Liang Wu Production Editor: Huan-Liang Wu

Antigenic differences between normal and malignant cells of the cancer patient form the rationale for clinical immunotherapeutic strategies. One emerging strategy in the treatment of tumors involves stimulation of an immunologic response against the neoplastic cells. The hope is that the immune system can be called into play to destroy malignant cells. However, in most instances, proliferating tumors do not provoke anti-tumor cellular immune responses. The precise mechanisms that enable antigenic neoplasms to escape host immunity are incompletely understood. The cells appear to escape recognition by the immune system in spite of the fact that neoplastic cells form weakly immunogenic tumor associated antigens.

The ultimate goal of cancer therapy is the elimination of every remaining tumor cell from the patient. It is unlikely that a single form of therapy is capable of achieving this goal. A number of papers in this special issue are presented which explore the various issues encountered with immunotherapeutic approaches to brain tumors. In particular one paper outlines the various clinical trials that have been attempted for treatment of brain tumors using various immunotherapeutic approaches. Although the results have been relatively modest, there is still enthusiasm for developing new and improved approaches with the speculation that immunotherapy will eventually play an important role in the treatment of brain tumors. Monitoring of the efficacy of immunotherapy remains an issue, and some important points regarding MRI techniques in monitoring these patients are outlined in another paper. The role of photodynamic therapy in the generation of specific anti-tumor immunity and vaccines for the treatment of brain tumors is outlined in one of the manuscripts. The specific problems encountered in developing immunotherapy for pediatric patients with brain tumors is a topic of another paper.

A number of exciting results have been found in patients with non-small cell lung cancer treated with immunotherapeutic approaches, and the issues involved in the treatment of these patients with tumors

(c) The Author(s) 2019. Open Access This article is licensed under a Creative Commons Attribution 4.0 International License (https://creativecommons.org/licenses/by/4.0/), which permits unrestricted use, sharing, adaptation, distribution and reproduction in any medium or format, for any purpose, even commercially, as long as you give appropriate credit to the original author(s) and the source, provide a link to the Creative Commons license, and indicate if changes were made.

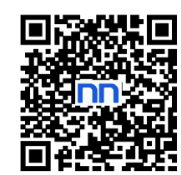


metastatic to the brain is the topic of one manuscript. Some issues regarding the interaction of hematopoietic stem cells in the immune response is a topic of another paper. A discussion of pharmacological strategies that interfere with glioma associated microglia/macrophage function which might be an alternative/ additional option to current approved cytotoxic regimens is reviewed in several manuscripts. Chimeric antigen receptor $\mathrm{T}$ (CAR-T) cells are being studied, both with systemic infusion and direct administration to the tumor and into the cerebrospinal fluid, with promising early results. A review aimed to discuss adoptive cell therapies with a focus on CAR-T treatment in patient with brain tumors is the topic of another manuscript. The therapeutic approach of adoptive lymphocyte transfer using lymphocytes primed and expanded ex vivo by exposure to total tumor RNA containing dendritic cells in certain pediatric patients with brain tumors is explored in another paper. A review of the current state of use of histone deacetylase (HDAC) inhibitors in gliomas, the mechanistic rationale for use of HDAC inhibitors in gliomas, and revelation of how certain HDAC inhibitors promote antitumor immunity in glioma patients is the focus of another manuscript. Finally a review of the immunosuppressive microenvironment generated by tumors along with various inhibitors that can impair these tumor immunosuppressive capabilities is outlined in another manuscript.

It is clear from the papers in this special issue that immunotherapy for brain tumors is being investigated from a number of different approaches, but significant enthusiasm remains that immunotherapy will be an important adjunct to the treatment of patients with brain tumors.

\section{DECLARATIONS}

\section{Authors' contributions}

Wrote entire review: Lichtor $\mathrm{T}$

\section{Availability of data and materials}

All papers referred to in this manuscript were published in the special issue.

\section{Financial support and sponsorship}

None.

\section{Conflicts of interest}

The author declared that there are no conflicts of interest.

\section{Ethical approval and consent to participate}

Not applicable.

\section{Consent for publication}

Not applicable.

\section{Copyright}

(C) The Author(s) 2019. 